OPEN ACCESS

Edited by:

Michat Wierzchoń

Jagiellonian University, Poland

Reviewed by:

Glenn Carruthers,

Charles Sturt University, Australia

Peter beim Graben,

Brandenburg University of

Technology Cottbus-Senftenberg,

Germany

${ }^{*}$ Correspondence:

Todd E. Feinberg

todd.feinberg@mountsinai.org

Specialty section:

This article was submitted to

Consciousness Research,

a section of the journal

Frontiers in Psychology

Received: 12 March 2019

Accepted: 03 July 2019

Published: 31 July 2019

Citation:

Feinberg TE and Mallatt J (2019)

Subjectivity "Demystified":

Neurobiology, Evolution, and the

Explanatory Gap.

Front. Psychol. 10:1686.

doi: 10.3389/fpsyg.2019.01686

\section{Subjectivity "Demystified": Neurobiology, Evolution, and the Explanatory Gap}

\author{
Todd E. Feinberg ${ }^{1 *}$ and Jon Mallatt ${ }^{2}$ \\ '/cahn School of Medicine at Mount Sinai, Psychiatry and Neurology, New York, NY, United States, ${ }^{2}$ The University of \\ Washington WWAMI Medical Education Program at The University of Idaho, Moscow, ID, United States
}

While life in general can be explained by the mechanisms of physics, chemistry, and biology, to many scientists and philosophers, it appears that when it comes to explaining consciousness, there is what the philosopher Joseph Levine called an "explanatory gap" between the physical brain and subjective experiences. Here, we deduce the living and neural features behind primary consciousness within a naturalistic biological framework, identify which animal taxa have these features (the vertebrates, arthropods, and cephalopod molluscs), then reconstruct when consciousness first evolved and consider its adaptive value. We theorize that consciousness is based on all the complex system features of life, plus even more complex features of elaborate brains. We argue that the main reason why the explanatory gap between the brain and experience has been so refractory to scientific explanation is that it arises from both life and from varied and diverse brains and brain regions, so bridging the gap requires a complex, multifactorial account that includes the great diversity of consciousness, its personal nature that stems from embodied life, and the special neural features that make consciousness unique in nature.

Keywords: primary consciousness, phenomenal consciousness, explanatory gap, neurobiology, subjectivity, evolution

\section{INTRODUCTION}

C.D. Broad in his classic book, The Mind and its Place in Nature, presented the difficulty of understanding how observable biological facts about the brain could explain experience. He described a thought experiment where he argued that even if an omniscient "mathematical archangel" had total knowledge of the chemistry of ammonia and the functions of the brain, the archangel still would not be able to explain or predict the smell of ammonia:

He [the archangel] would know exactly what the microscopic structure of ammonia must be; but he would be totally unable to predict that a substance with this structure must smell as ammonia does when it gets into the human nose. The utmost that he could predict on this subject would be that certain changes would take place in the mucous membrane, the olfactory nerves and so on. But he could not possibly know that these changes would be accompanied by the appearance of a smell in general or of the peculiar smell of ammonia in particular, unless someone told him so or he had smelled it for himself (Broad, 1925, p. 71; also see Jackson, 1986). 
Levine (1983) called the apparent divide between objective explanations of brain functions and their accompanying subjective feelings the explanatory gap. In the following quote from his paper, he applies the gap to the lack of a clear connection between the objective neurons that transmit pain (C-fibers) and the subjective experience of pain itself:

However, there is more to our concept of pain than its causal role, there is its qualitative character, how it feels; and what is left unexplained by the discovery of C-fiber firing is why pain should feel the way it does! For there appears to be nothing about $\mathrm{C}$-fiber firing which makes it naturally "fit" the phenomenal properties of pain, any more than it would fit some other set of phenomenal properties... The identification of the qualitative side of pain with C-fiber firing (or some property of C-fiber firing) leaves the connection between it and what we identify it with completely mysterious. One might say, it makes the way pain feels into merely brute fact (Levine, 1983, p. 357).

The subjective, qualitative aspect of consciousness that concerns Levine has been called phenomenal consciousness, primary consciousness, sensory consciousness, having any feelings, and experiencing phenomenal properties (which are perceived qualities, alternately called the phenomenal characters of experience and qualia). As defined by Antti Revonsuo, this basic form of sensory experience does not have to be elaborate, lingering, reflective, or human-like to be conscious:

The mere occurrence or presence of any experience is the necessary and minimally sufficient condition for phenomenal consciousness. For any entity to possess primary phenomenal consciousness only requires that there are at least some patterns --- any patterns at all --of subjective experience present-for-it. It is purely about the having of any sorts of patterns of subjective experience, whether simple or complex, faint or vivid, meaningful or meaningless, fleeting or lingering (Revonsuo, 2006, p. 37).

Related to Levine's "gap" is what Philosopher David Chalmers called the problem of the character of conscious experience:

Why do individual experiences have their particular nature? When I open my eyes and look around my office, why do I have this sort of experience? At a more basic level, why is seeing red like this, rather than like that! ....Why is the experience one way rather than the other? Why, for that matter, do we experience the reddish sensation that we do, rather than some entirely different sensation, like the sound of a trumpet? (Chalmers, 1996, p. 5).

So just like Broad wondered how the chemistry of ammonia and the functions of the brain could explain the particular smell of ammonia and Levine pondered the explanatory gap between the brain and the specific qualities of subjective experience, Chalmers wants an explanation of how brain processes could explain why pain feels the particular way "pain" feels. And why are there differences between the subjective feel of "red," the note "C-sharp," and feeling "happy" or "sad"? So all these writers are asking similar questions: how does the brain create the specific qualities of subjective experience?

In this paper, we argue that several biological principles are needed to explain the complex biological mechanisms behind feelings (Figure 1). First, animal feelings are built on the foundations of the general features of life, plus additional simple and complex neuronal reflexes, and then on core-brain functions (Feinberg and Mallatt, 2016a, 2018a; Lacalli, 2018). Next, to these are added a set of "special neurobiological

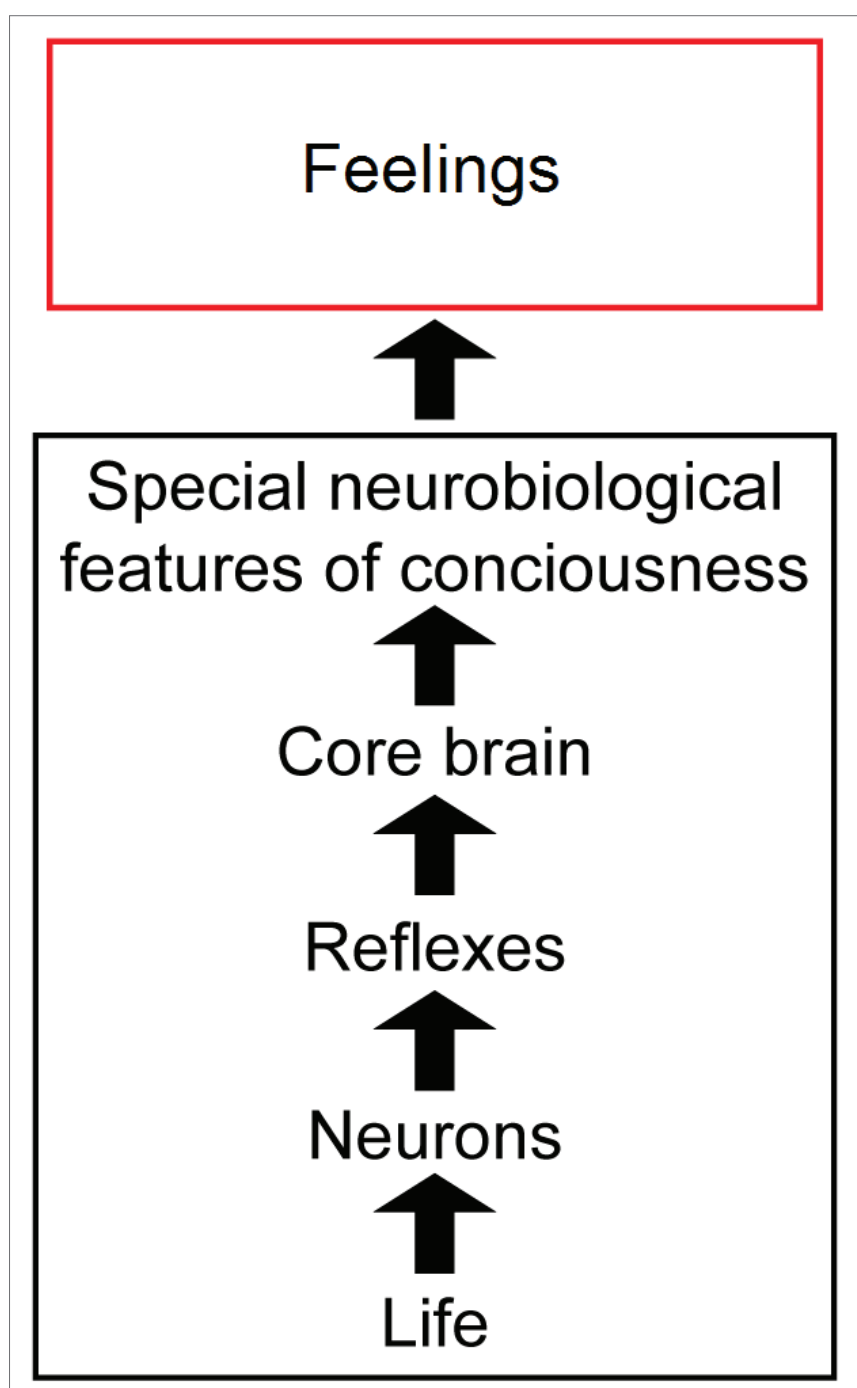

FIGURE 1 | Overview of our theory of consciousness. The sequence from physical life through conscious feelings. Life and the special features of consciousness are emphasized most. The images are reproduced with the permission of the copyright holder Mount Sinai Health System. 
features" of consciousness, which are diverse, distributed, and in fact are unique to conscious brains and indeed unique in all of nature. But the multifactorial and diverse bases of feeling, in addition to its biological uniqueness, make the connections between the neural mechanisms of feeling and the experience of feeling difficult to define in a discrete or parsimonious manner. Nonetheless, the connections can be understood in an unmysterious, scientific way. Note that we use the term "feelings" to mean all kinds of experiences, not just the affective or emotional experiences as it is sometimes used.

\section{SOME REASONS WHY EXPLAINING THE "GAP" IS SO DIFFICULT: THE MANY, DIVERSE MECHANISMS BEHIND CONSCIOUSNESS}

\section{Mechanisms Include General Life Functions and Reflexes}

The general functions of life include growth, metabolism, coded information, adaptation, and more (Mayr, 2004). That the general life functions contribute to consciousness is supported by the numerous commonalities between these functions and conscious feelings (Table 1). Namely, both life and consciousness are embodied, both are processes, both are unique features of complex, hierarchically organized systems (cellular and neural, respectively), and both are the result of their systems' subparts and the subparts' interactions (Atmanspacher, 2015; Nunez, 2016; Feinberg and Mallatt, 2016a; Solms, 2019). In fact, one can view consciousness as an elaboration of the interactions of multicellular life's most complex cells, the neurons.

Especially important for understanding the basis of feeling is that both life and feeling are embodied. Thus, as each living organism has a body with a boundary from the outer world, so consciousness needs a body for a subject to have a personal (first-person) point of view (see for instance, Thompson, 2007).

There are critical ways in which consciousness goes beyond basic life, in needing a body with many cells, neurons that communicate by action potentials and synapses, nervous reflexes, and even a basic, core brain. These necessary elements are not sufficient for consciousness, however, because some animals have them yet seem to operate only by reflexes and basic motor programs (most worms and slugs:

TABLE 1 | Features that consciousness shares with life.

Cell as a key unit

Embodiment: in a body with a boundary

Process: mechanisms and functions are performed by actions of the individual parts

System: in which interactions between the parts are critical

Hierarchy: the system has different, interacting levels, of increasing complexity
Klein and Barron, 2016; Feinberg and Mallatt, 2016a, 2018a). Something more is necessary.

\section{The Mechanisms of Consciousness Require the Special Neurobiological Features}

This "something more" is a set of special neurobiological features of complex brains, which combined with the more basic life functions, reflexes, and core brain, create consciousness. We deduced these special features from simple premises (Feinberg and Mallatt, 2018a,b). First, we assumed all animals with brains that organize their sensory inputs into detailed, multisensory, and mapped representations of the world and body can consciously experience sensory mental images (Figure 2). Indeed such neural maps-more multisensory, unified, and complex than known computers and artificial intelligence can achieve (LeCun et al., 2015) - are often considered to be a marker for primary consciousness (Edelman, 1992; Damasio, 2010). Second, we assumed that all animals capable of global operant learning learning new, complex survival behaviors from experience based on rewards and punishments-can feel positive and negative effects, and thus, they have the affective type of consciousness (akin to felt human emotions). Our logic for this was that if an animal first reacts to the rewarding or punishing stimuli, then shows through complex behavior that it remembered the stimuli, it must have felt them in the first place (see Feinberg and Mallatt, 2016a; and Bronfman et al., 2016 added important considerations). Third, we identified the animal clades that fit these criteria-all the vertebrates, cephalopod molluscs, and arthropods-and examined their neurobiology to uncover still more neural and behavioral features associated with consciousness. Through these three steps, we built our set of special features of consciousness (Table 2).

Invertebrate consciousness is debated, so we will consider it closer here. Actually, consciousness in the cephalopod octopuses and squids is not so controversial because investigators recognize the sharp senses of these animals, the close attention they pay to their surroundings, and their advanced learning abilities (Mather and Carere, 2016; Godfrey-Smith, 2016a). The real controversy is about whether insects and other arthropods have consciousness. Although we exhaustively assembled the evidence for this in our previous works (Feinberg and Mallatt, 2016a, 2018a; also see Klein and Barron, 2016), we will review that evidence we found most suggestive. Bees can see, learn, and remember a complexly patterned target for finding food (suggesting image-based consciousness: Fauria et al., 2000), and they pass the "judgment bias test" (i.e., are more likely to choose an ambiguous cue toward a reward if they just received a sample of that reward: Perry et al., 2016). Judgment bias is a standard test for positive affective consciousness in animals, and passing it is said to indicate that one feels an anticipated reward. Lest it seem that arthropod consciousness only applies to the relatively large-brained bees, jumping spiders also show evidence for it. These spiders can follow the route to their prey after just temporarily seeing that prey from a distance, suggesting they form mapped, mental images (Jackson and Cross, 2011; Perry and Chittka, 2019). Also, all arthropod 


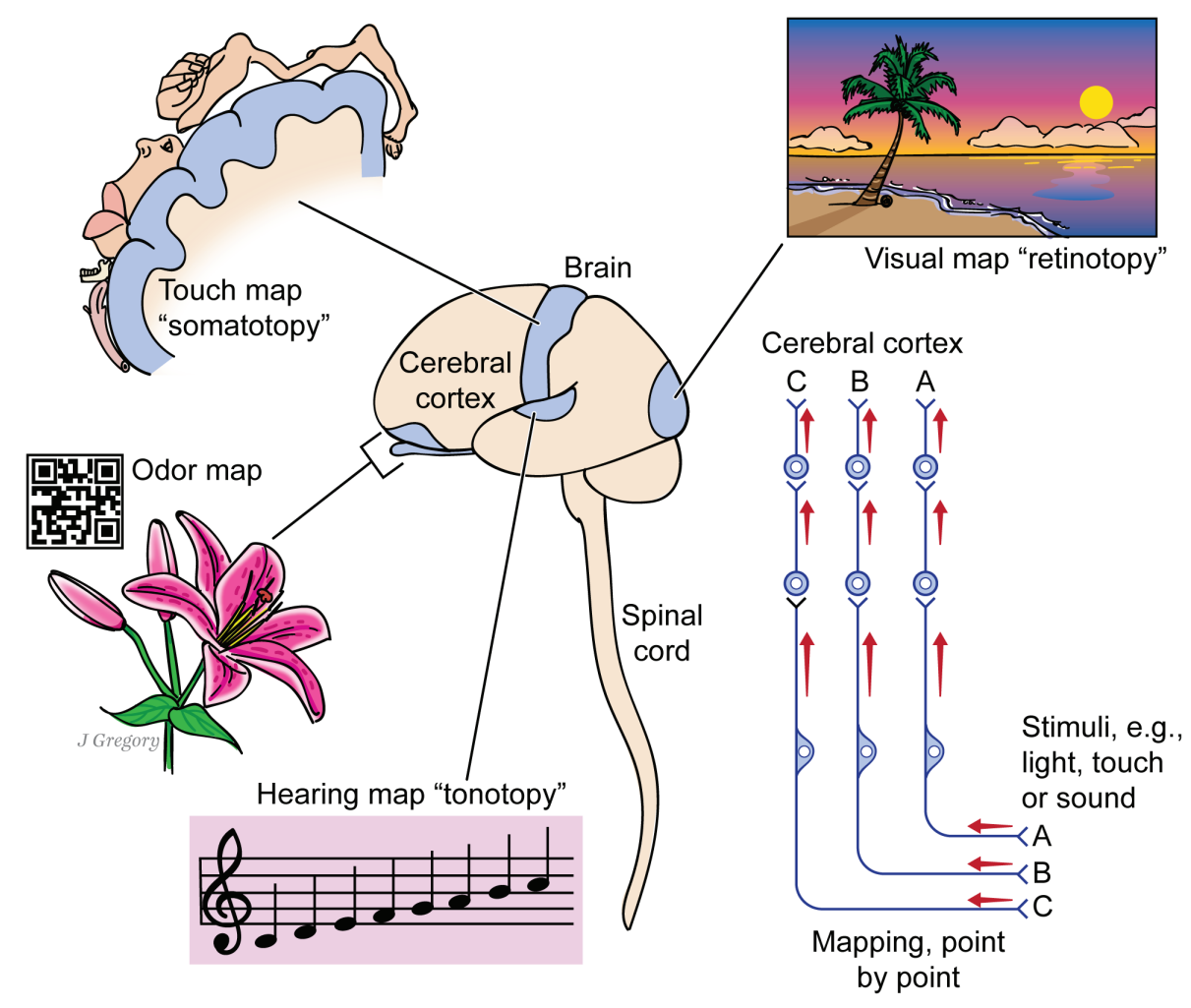

FIGURE 2 | The image-based kind of consciousness involves the brain mapping the sensed world. A human brain and spinal cord are shown at center. The cerebral cortex processes mapped signals from different senses: from vision, whose mapping of the visual field is called retinotopy; from the touch senses whose mapping of the body parts is somatotopy; from the sense of smell, which forms an odor map like a bar code; and from the auditory sense, whose mapping of sounds by pitch is tonotopy. The picture at right shows that each kind of sensory signal reaches the cerebral cortex through a chain of several neurons, while maintaining its point-by-point mapping through the entire route. Some animals have no cerebral cortex yet have such maps in other higher brain centers. (From Consciousness Demystified, MIT, 2018. The images are reproduced with the permission of the copyright holder Mount Sinai Health System.)

brains are built on the same plan and have the same parts (Strausfeld, 2012), even that of the earliest fossil arthropods from 520 million years ago (Ma et al., 2012). This suggests all arthropods have had consciousness from the beginning.

Let us cover the special features in Table $\mathbf{2}$ more systematically. We have documented how this set of vertebrate-arthropodcephalopod features is absent from animals with simpler nervous systems: namely from all the other invertebrates, the nonconscious worms, jellyfish, clams, sea squirts, sea stars, etc. (Feinberg and Mallatt, 2013, 2016a). The features include an explosion of special senses (image-forming eyes, acute hearing, and keen smell) and of neuron types; many new neural processing subsystems; more integration of information from the different senses; more hierarchic levels of neurons for processing information; extreme reciprocal and oscillatory crosscommunication between the lower and higher levels and between participating brain regions (Lamme, 2006; Koch et al., 2016; Northoff, 2016; Nunez, 2016; Grossberg, 2017); more effective attention; and more memory. From these features arise the extraordinary neurobiological system-properties of complex brains in a way comparable to how life naturally arises from the interactions of its subcellular and cellular components. But these neurobiological features are even more remarkable for the creation of consciousness than are those that create life: together they are unique to conscious brains - and indeed are unique in all of nature - so it should come as no surprise, nor present an unfathomable mystery, that they produce something unique in nature like feelings.

This leads to the question of the adaptive role of consciousness in animals that have it. We analyzed the literature and came up with a list of adaptive functions (Table 3; Feinberg and Mallatt, 2018a). Foremost among these are that consciousness efficiently codes and organizes large amounts of sensory input into a unified set of phenomenal properties for choosing among many active responses, and that its unified simulation of the subject's body moving through complex environments allows survival and reproduction in the wild (Cabanac, 1996; Seth, 2009; Klein and Barron, 2016; Merker, 2016).

We claim that consciousness evolved naturally, so this demands an account of when consciousness appeared, without any inexplicable gaps in the evolutionary sequence. Indeed, in the fossil record, we traced the evolution of consciousness and brains in an unbroken chain from blind and brainless marine worms to the first arthropods and vertebrate fish in the Cambrian seas, from about 560 or 540-520 million years ago (Feinberg and Mallatt, 2016a,b, 2018a,b). This sequence is shown in Figure 3. 
TABLE 2 | The special neurobiological features of consciousness (mostly after Feinberg and Mallatt, 2018a).

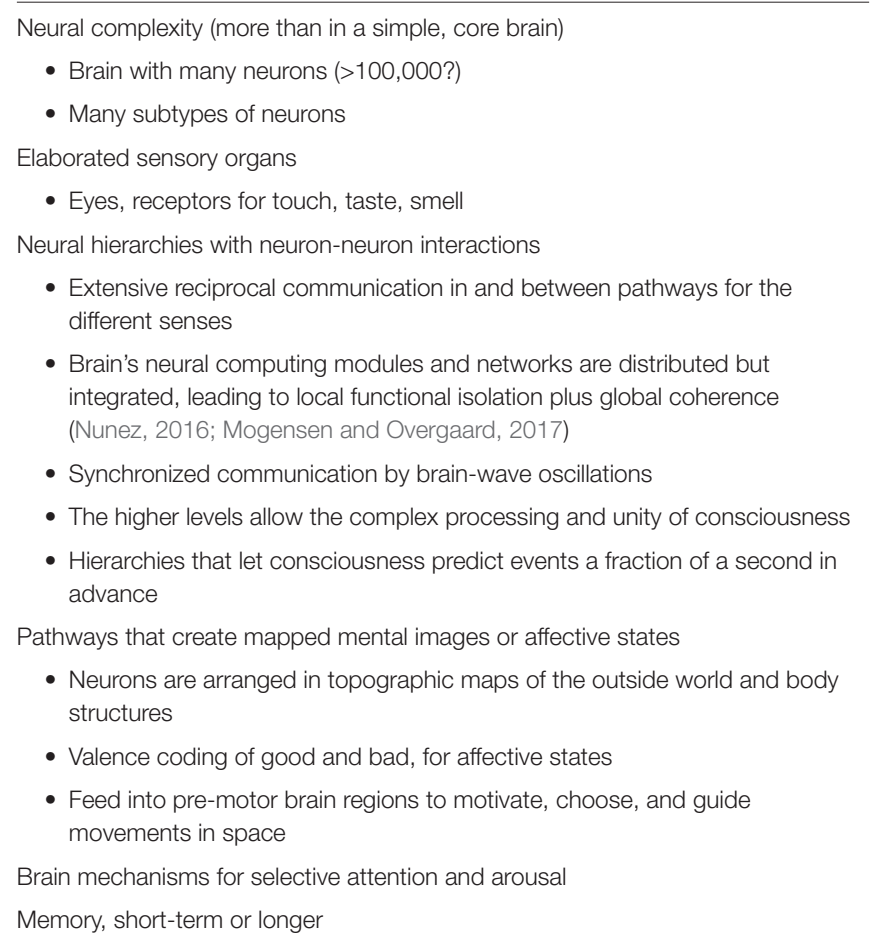

TABLE 3 | Some adaptive roles of consciousness (mostly after Feinberg and Mallatt, 2018a).

Organizes large amounts of sensory input into a set of phenomenal properties for action choice

Its unified simulation of the sensed world directs behavior in this world It ranks sensed stimuli by importance, by assigning affects to them, making decisions easier

Allows flexible behavior because it sets up many different behavioral choices Allows easily adjustable behavior because it predicts the consequences of one's actions into the immediate future (Perry and Chittka, 2019; Solms, 2019)

Deals well with new situations, to meet the changing challenges of complex environments

The stimulus would have been the rise of Earth's first animalon-animal predators. That led to natural selection for sharp vision and other distance senses that mapped space into a detailed, panoramic mental image to deal with the predation. The images also allowed animals to navigate accurately through complex environments. Furthermore, the predation led to selection for the affective "emotions" to drive elaborate escapes, attacks, approach behaviors, etc. (Merker, 2005; Plotnick et al., 2010; Trestman, 2013; Klein and Barron, 2016; Godfrey-Smith, 2016b).

So far, here are our conclusions about the mechanisms for consciousness. We deduced first that feelings uniquely connect to the embodied life of the organism, and second, they have a unique neurobiology through the set of special features. By contrast, most other scientific explanations of consciousness include the special features alone, which are often called the neural correlates of consciousness (e.g., Seth et al., 2005; Koch et al., 2016). However, we feel it necessary also to include the foundations of consciousness in life functions, which require only normal physics, chemistry, and evolutionary processes, to remove a big part of the "mystery" from consciousness and from its mechanisms.

\section{The Mechanisms of Consciousness Are Diverse}

Many different theories address the causes and mechanisms of consciousness. Some promote single-factor causes: e.g., panpsychism ${ }^{1}$; consciousness as a fundamental force (Chalmers, 1996); and quantum microtubules (Hameroff and Penrose, 2014). Other theories recognize consciousness to be complex and multifactorial but emphasize a major factor or approach: e.g., a global workspace (Baars et al., 2013); information (Tononi and Koch, 2015; Nunez, 2016); cognitive and computational aspects (Dehaene, 2014; Piccinini, 2015; Dehaene et al., 2017); reciprocal and oscillatory neuronal communications (Lamme, 2006; Koch et al., 2016); the attentional aspects (Tsuchiya and van Boxtel, 2013; Graziano and Webb, 2015); instinct (Gazzaniga, 2018); complex new physics (Primas, 2007; Nunez, 2016; Torday and Miller, 2018); predictive properties (Solms, 2019); and contextual emergence in systems theory (Atmanspacher and beim Graben, 2009; Atmanspacher, 2015). We call these the "major-mechanism theories." While these theories all make valid contributions to explaining the mechanisms of consciousness, our findings indicate that consciousness is even more diverse than any one of them proposes. Here, we summarize the remarkable diversity of consciousness, from multiple perspectives (Table 4).

To begin with, we found that sensory consciousness, from the standpoint of its neural and functional properties, should be divided into three partially overlapping domains or subtypes: exteroceptive, affective, and interoceptive. Exteroceptive phenomenal properties are created from mapped, sensory mental images of the world (from what is seen, heard, smelled, etc.); affective feelings are internal, valenced feelings, both positive and negative (as in emotions); and interoceptive phenomenal properties are in-between, including both mapped sensory representations of the body's organs and the affective feelings that protect somatic functions.

Most existing theories tend to cover just one of these subtypes, such as the exteroception-based theories of Edelman (1989, 1992) and Tsuchiya et al. (2015); emotion-centered theories of Denton (2006); Damasio (2010); Nummenmaa et al. (2018), and Solms (2019); and interoception-based studies of Craig (2010) and Vierck et al. (2013). We, on the other hand, cover all three subtypes, considering both their differences and commonalities.

Not only are these three domains different manifestations of consciousness but they also, beyond sharing the special neurobiological features, have different neural architectures.

${ }^{1}$ https://plato.stanford.edu/entries/panpsychism/ 


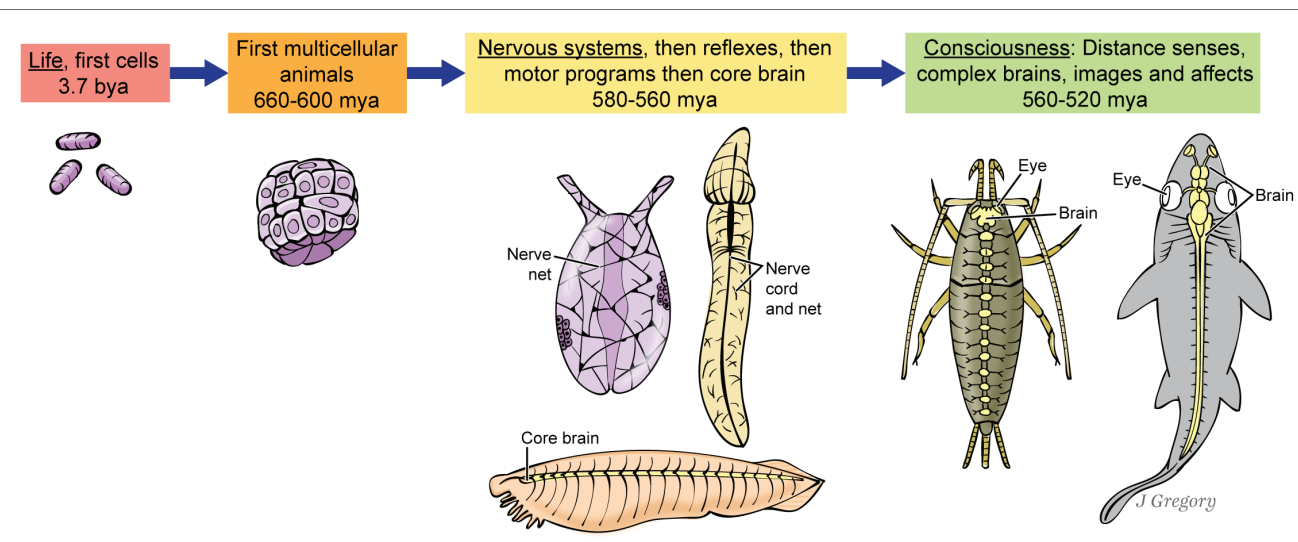

FIGURE 3 | Proposed stages in the evolution of consciousness, as an uninterrupted sequence. The three animals at the 'Nervous system' stage at center are hypothetical, but based roughly on a sea anemone, a hemichordate acorn worm, and the fish-like invertebrate, amphioxus. The two animals at far right are a bristletail insect and a shark. (From Consciousness Demystified, MIT, 2018. The images are reproduced with the permission of the copyright holder Mount Sinai Health System.)

TABLE 4 | Ways in which consciousness is diverse.

A. Three subtypes
- Exteroceptive
- Affective
- Interoceptive
B. Brain regions (mammal example)
- Cerebral cortex (mapped images)
- Subcortical (affects)
C. The coding varies: mapped representations of space versus valence-coding
D. Hubs and nodes are widely distributed within brains
E. In different animal groups
- Vertebrates
- Arthropods
- Cephalopods

In mammals, for example, exteroceptive phenomenal properties stem more from the cerebral cortex, whereas affective feelings stem more from subcortical parts of the cerebrum, the hypothalamus, and brain stem. This two-site interpretation is not fully accepted, as some investigators say all types of mammalian consciousness stem from the cerebral cortex (e.g., Craig, 2010; LeDoux and Brown, 2017; Nummenmaa et al., 2018). However, it is supported by the fact that children born with little or no cerebral cortex (a condition called hydranencephaly) show strong emotional behaviors, as do mammals from which the cerebral cortex was experimentally removed (Panksepp, 2005; Aleman and Merker, 2014). For more discussion, see Feinberg and Mallatt (2018a).

Exteroceptive circuits are organized to encode a mapped representation of space (Edelman, 1989; Stein and Meredith, 1993), whereas affective circuits encode positive and negative valences instead (Shao et al., 2017; Adolphs and Anderson, 2018; Corder et al., 2019).

As more evidence that consciousness is not monolithic, its neural substrates are widespread within brains. This is now widely recognized, and Nunez (2016) gives an especially good account. For us, it is seen best for the affective circuits in vertebrates, which involve interconnected hubs spread over such distant areas as the amygdala and basal forebrain, midbrain, hypothalamus, and habenula of the diencephalon (Hu, 2016). And the reticular formation, which distributes through much of the vertebrate brain stem, projects very widely to control the attention and arousal aspects of consciousness (Schiff, 2008; Brodal, 2016). In insects, which we likewise deduced to have consciousness, the neurons for arousal and attention also distribute widely through the brain (Van Swinderen and Andretic, 2011).

Still more demonstration that phenomenal properties and their neural substrates are extremely diverse and widespread comes from cross-species comparisons. The vertebrates, arthropods, and cephalopods evolved brains entirely independently, from a brainless common ancestor (Northcutt, 2012). Thus, they all evolved the brain regions for consciousness separately, by convergent evolution (Edelman, 2016). For a vertebrate, an insect, and an octopus, we mapped the brain regions that associate with various aspects of consciousness, from image-based consciousness to the participating memories (Figure 4), and found that these regions look different and have different relative locations in the three animal brains (Feinberg and Mallatt, 2018a). Apparently, primary consciousness can stem from very different brain substrates.

To summarize, the multifactorial basis of conscious experience, including its foundations in life processes, its widespread neural organization, its diversity both within and across species, and its uniqueness in biology and indeed all of nature, make it exceedingly difficult if not impossible to encapsulate or "pinpoint" its biological and neurobiological substrate and cause in the way, for instance, that photosynthesis can account for energy creation in plants or that DNA can account for the mechanisms of hereditary.

But while this complexity makes it difficult to learn how brains create experience, this does not mean the process is mysterious or unexplainable. Many complex biological functions-including life itself-are multi-determined aggregate 


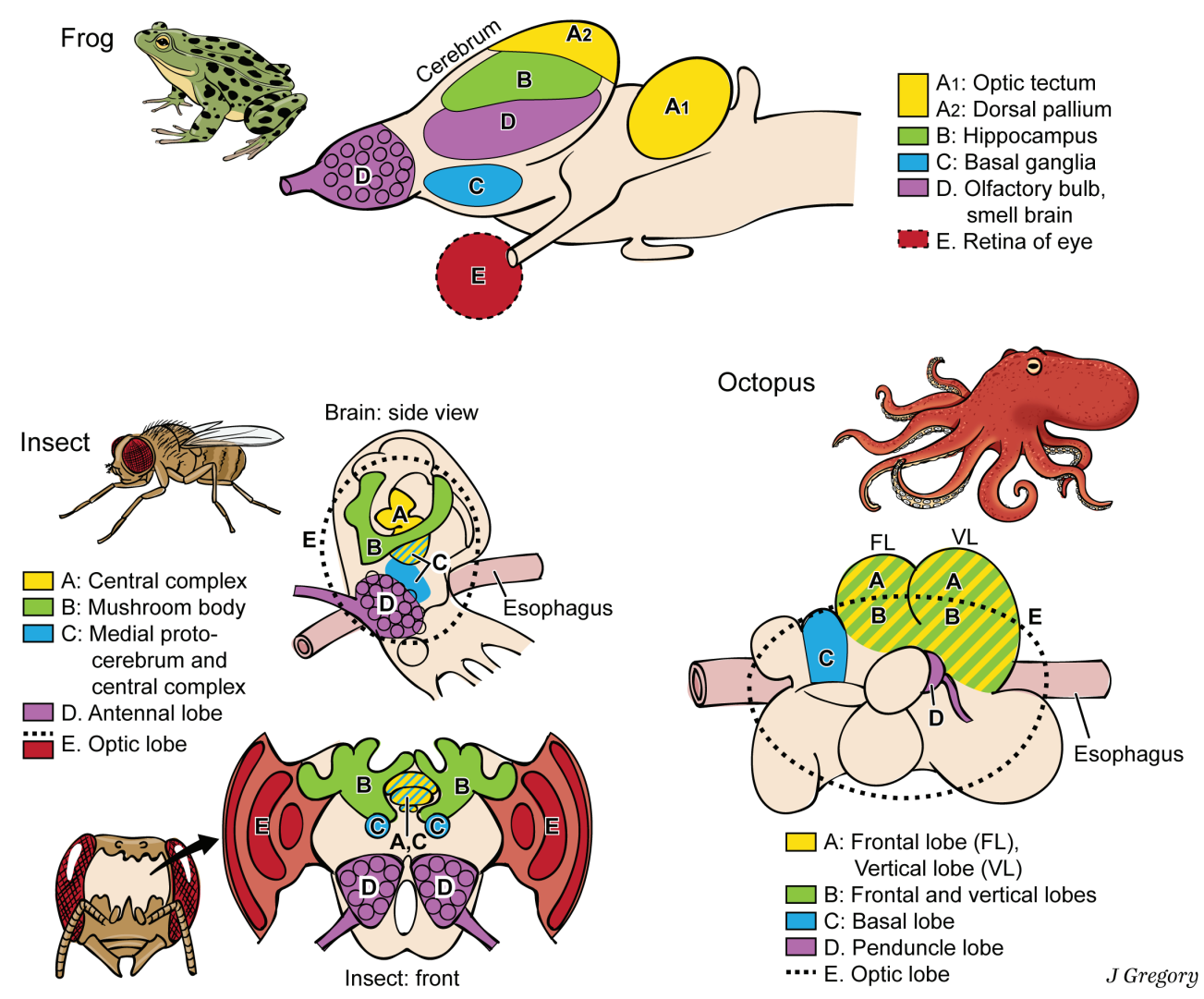

FIGURE 4 | Dissimilar brains of three different taxa of animals with consciousness. The areas with similar functions are colored the same in the different brains. The general code is: A, image-based consciousness; B, memory; C, pre-motor center; D, smell processing; and E, visual processing. (From Consciousness Demystified, MIT, 2018. The images are reproduced with the permission of the copyright holder Mount Sinai Health System.)

functions that cannot be reduced to a few factors, yet are nonetheless scientifically explainable (Von Bertalanffy, 1952; Mayr, 2004; Drack, 2015).

\section{CAN THE PERSONAL (SUBJECTIVE) NATURE OF SENSORY CONSCIOUSNESS HAVE A NATURAL (BIOLOGICAL) EXPLANATION?}

Despite the phenomenal and neurobiological diversity, we propose that the subjective, phenomenal, aspects of experience can be explained using the principles of normal physics, chemistry, and biology. The question is how?

Our answer is best broken down into two parts. First, as we argued above, because phenomenal properties are built upon life, and both life and consciousness are system features of embodied organisms, then it follows that consciousness is personal and unique to the living organism. Seen in this light, these feelings are aggregate functions of certain complex, personal (living) brains, from which they cannot be dissociated. This is true whether we are talking about such different feelings as red, pain, hunger, or happiness. Essential is the fact that the feeling of red is a personally specific and neurobiologically unique feature of an individual's particular brain state, as are all phenomenal properties. Therefore, certain complex neural features of this system, could, unmysteriously, result in a unique, personal system-feature like subjective experience, just like "life" is a personal system feature of complex living organisms. Thus, life itself provides the initial conditions for the subjectivity of experience.

But second, to this we must add the features of increased complexity and neurobiological uniqueness of the special features that are ultimately responsible for both the creation of - and the specific qualities of - subjective experience. The special features are numerous and enormously complex, but we derived them scientifically and they are entirely biologically natural (see Table 2 and the associated text). Add to this the aforementioned personal aspect of subjective experience, due to its basis in the embodied life processes of the individual organism, and then the combination of these factors-complex neurobiological uniqueness walled off within personal embodiment-makes consciousness appear "mysterious" and inexplicable by known physical law. But we did not need to invoke a "mysterious" explanation to account for the personal and unique aspects of subjectivity.

Now, what of Chalmers question about the specific character of conscious experience? Why is a color experienced differently from a sound or pain? The answer lies in the diverse neurobiology 
behind these varied subjective experiences. For instance, it is clear that the neural pathways of color processing, sound processing, pain processing, affect and so on show enormous neurobiological differences (Brodal, 2016; see Feinberg and Mallatt, 2016a, for further discussion). Electromagnetic waves of light have many different physical properties than the mechanical forces of touch, and both differ from chemical odorants, so translating all three kinds of stimuli into similar feelings would miss the special properties that make each sense so especially informative. Therefore, these diverse sensations should not - and indeed could not - all have the same subjective "feel." It should come as no surprise that the phenomenal experiences created by these varied neural architectures differ in how they are subjectively experienced. In other words, the qualitative features of phenomenal properties lie in the neural states themselves; they are not an "additional feature" to the neural states that create them.

\section{DISCUSSION}

We have built the case that there are no scientific "gaps" in the neurobiology and evolution of consciousness, but rather a seamless series of transitions between levels of increasing neural differentiation, complexity, and hierarchy that lead to phenomenal consciousness. We find that with this approach we do not need to posit any new, singular or fundamental "physical" factor that explains the unique and personal nature of phenomenal consciousness. Here, we summarize the major points in this argument.

\section{Consciousness Has Its Foundations in Life Itself}

The neurobiological mechanisms of consciousness that we identified have their foundations in embodied life and simpler nervous elements (Table 1). The later-evolving and more-complex special neurobiological features of advanced brains are built upon and derived from the general features of life, which they retain.

The role that the features of life play in the creation of consciousness has actually been noted by some philosophers who are interested in explaining consciousness (Churchland, 1996, 2013; Thompson, 2007). For instance, Evan Thompson argued that the failure to appreciate the relationship between life processes and consciousness mistakenly draws an "unbridgeable divide" between the physical brain on the one hand and experience (feeling) on the other, a mistake that in essence disregards all the general biological features that can help explain consciousness and how subjectivity is created:

I have argued that the standard formulation of the hard problem is embedded in the Cartesian framework of the "mental" versus the "physical," and that this framework should be given up in favor of an approach centered on the notion of life or living being. Although the explanatory gap does not go away when we adopt this approach, it does take on a different character.
The guiding issue is no longer the contrived one of whether a subjectivist concept of consciousness can be derived from an objectivist concept of the body. Rather, the guiding issue is to understand the emergence of living subjectivity from living being, where living being is understood as already possessed of an interiority that escapes the objectivist picture of nature (Thompson, 2007, p. 236).

Thus, embodied life ultimately gives subjectivity its personal nature. But as Thompson notes, the explanatory gap by no means goes away simply because consciousness is a feature of life. Life partly fills that gap but something more is needed something uniquely neurobiological is required to explain the transition from life to the unique and personal features of phenomenal consciousness. That 'added something' would be the special neurobiological features.

\section{The Special Features Are Critical to the Creation of Consciousness}

Like life, consciousness is an aggregate property of certain less-complex properties. But there is a difference. Cells, tissues, or organs can still be "alive" individually because they do not rely on higher hierarchical levels for their "living properties." For consciousness, by contrast, while its lower-level neural elements like individual neurons or reflex arcs are all independently alive, the aggregate property of "consciousness," which includes both living properties and complex, hierarchical, neural properties, does not emerge until much higher levels are added (the special features of Table 2).

\section{The Neurobiology of Consciousness Is Diverse}

According to our approach, many different neurobiological architectures are capable of creating different manifestations of phenomenal consciousness. Although these share the special features of Table 2, their great diversity both within brains and across animal phyla and their multifactorial and neurobiologically widespread origins in brains make it impossible to discretely, exactly, and simply define consciousness's biological and neurobiological basis. Thus, we cannot explain all feeling states as derived from the same neurobiological elements. Even if it were "one thing," the aggregate phenomenon of consciousness has many diverse aspects and pathways. And many different major-mechanism theories may apply (global workspace, informational, computational, etc.). The recognition that consciousness is even more diverse and widespread than previously realized can encourage the many existing theories to come together and integrate their approaches.

\section{Consciousness Is Neurobiologically Unique}

The set of special features is novel and unique in biology, and hence, they contribute to the uniqueness of consciousness in nature. Consciousness is best viewed as a unique but 
TABLE 5 | Consciousness is demystified, as.

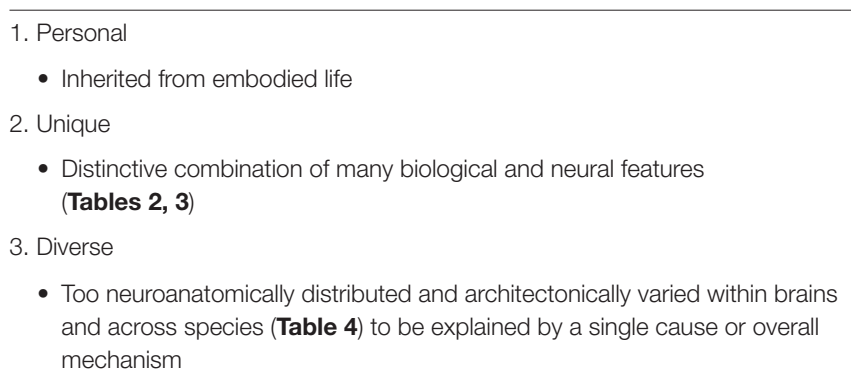

multi-determined aggregate system feature of life and complex brains. This uniqueness makes consciousness difficult to study because consciousness cannot be compared to anything else, but it is not mysterious. And this view does not require that we explain all the mechanisms of subjective experience within the solution. The "gap" is best explained by the combination of several critical factors - the personal embodiment of subjectivity

\section{REFERENCES}

Adolphs, R., and Anderson, D. (2018). The neuroscience of emotion. A new synthesis. Princeton, NJ: Princeton University Press.

Aleman, B., and Merker, B. (2014). Consciousness without a cortex: a hydranencephaly family survey. Acta Paediatr. 103, 1057-1065. doi: 10.1111/apa.12718

Atmanspacher, H. (2015). Contextual emergence of mental states. Cogn. Process. 16, 359-364. doi: 10.1007/s1033

Atmanspacher, H., and beim Graben, P. (2009). Contextual emergence. Scholarpedia 4:7997. doi: 10.4249/scholarpedia.7997

Baars, B. J., Franklin, S., and Ramsoy, T. Z. (2013). Global workspace dynamics: cortical "binding and propagation" enables conscious contents. Front. Psychol. 4:200. doi: 10.3389/fpsyg.2013.00200

Broad, C. D. (1925). The mind and its place in nature. New York, NY: Harcourt Brace \& Company, Inc.

Brodal, P. (2016). The central nervous system. Structure and function. 5th edn. New York: Oxford University Press.

Bronfman, Z. Z., Ginsburg, S., and Jablonka, E. (2016). The transition to minimal consciousness through the evolution of associative learning. Front. Psychol. 7:1954. doi: 10.3389/fpsyg.2016.01954

Cabanac, M. (1996). On the origin of consciousness, a postulate and its corollary. Neurosci. Biobehav. Rev. 20, 33-40. doi: 10.1016/0149-7634(95)00032-A

Chalmers, D. J. (1996). The conscious mind: In search of a fundamental theory. New York, NY: Oxford University Press.

Churchland, P. S. (1996). The hornswoggle problem. J. Conscious. Stud. 3, 402-408.

Churchland, P. M. (2013). Matter and consciousness. Cambridge, MA: MIT press.

Corder, G., Ahanonu, B., Grewe, B. F., Wang, D., Schnitzer, M. J., and Scherrer, G. (2019). An amygdalar neural ensemble that encodes the unpleasantness of pain. Science 363, 276-281. doi: 10.1126/science.aap8586

Craig, A. D. (2010). The sentient self. Brain Struct. Funct. 214, 563-577. doi: 10.1007/s00429-010-0248-y

Damasio, A. (2010). Self comes to mind: Constructing the conscious brain. New York, NY: Vintage.

Dehaene, S. (2014). Consciousness and the brain: Deciphering how the brain codes our thoughts. New York, NY: Viking Penguin.

Dehaene, S., Lau, H., and Kouider, S. (2017). What is consciousness, and could machines have it? Science 358, 486-492. doi: 10.1126/science.aan8871

Denton, D. (2006). The primordial emotions: The dawning of consciousness. Oxford: Oxford University Press.

Drack, M. (2015). Ludwig von Bertalanffy's organismic view on the theory of evolution. J. Exp. Zool. B Mol. Dev. Evol. 324, 77-90. doi: 10.1002/jez.b.22611 that derives from life, with the unique, complex, and diverse neurobiological features that contribute to consciousness.

Table 5 summarizes, in simplest form, how we fill the explanatory gap and demystify consciousness.

\section{AUTHOR CONTRIBUTIONS}

For this paper, TF focused more on the theory, philosophy, and neurobiology and JM focused more on the neurobiological and evolutionary aspects.

\section{ACKNOWLEDGMENTS}

The authors thank Jill K. Gregory at the Instructional Technology, Icahn School of Medicine at Mount Sinai, for the professional artwork of the figures. They also thank several reviewers for their helpful comments.

Edelman, G. M. (1989). The remembered present: A biological theory of consciousness. New York: Basic Books.

Edelman, G. M. (1992). Bright air, brilliant fire: On the matter of the mind. New York: Basic books.

Edelman, D. B. (2016). Leaving the door open for fish pain: evolutionary convergence and the utility of 'just-so stories'. Anim. Sent. 1, 1-4.

Fauria, K., Colborn, M., and Collett, T. S. (2000). The binding of visual patterns in bumblebees. Curr. Biol. 10, 935-938. doi: 10.1016/ S0960-9822(00)00623-0

Feinberg, T. E., and Mallatt, J. (2013). The evolutionary and genetic origins of consciousness in the Cambrian Period over 500 million years ago. Front. Psychol. 4:667. doi: 10.3389/fpsyg.2013.00667

Feinberg, T. E., and Mallatt, J. (2016a). The ancient origins of consciousness: How the brain created experience. Cambridge, MA: MIT Press.

Feinberg, T. E., and Mallatt, J. (2016b). The nature of primary consciousness: a new synthesis. Conscious. Cogn. 43, 113-127. doi: 10.1016/j. concog.2016.05.009

Feinberg, T. E., and Mallatt, J. (2018a). Consciousness demystified. Cambridge, MA: MIT Press.

Feinberg, T. E., and Mallatt, J. (2018b). Unlocking the "mystery" of consciousness. Scientific American, Observations. Available at: https://blogs.scientificamerican. com/observations/unlocking-the-mystery-of-consciousness/ (Accessed July 12, 2019).

Gazzaniga, M. S. (2018). The consciousness instinct: Unraveling the mystery of how the brain makes the mind. New York: Farrar, Straus and Giroux.

Godfrey-Smith, P. (2016a). Other minds: The octopus, the sea, and the deep origins of consciousness. London: Macmillan.

Godfrey-Smith, P. (2016b). "Animal evolution and the origins of experience" in How biology shapes philosophy: New foundations for naturalism. ed. D. L. Smith (Cambridge: Cambridge University Press), 23-50.

Graziano, M. S., and Webb, T. W. (2015). The attention schema theory: a mechanistic account of subjective awareness. Front. Psychol. 6:500. doi: 10.3389/fpsyg.2015.00500

Grossberg, S. (2017). Towards solving the hard problem of consciousness: the varieties of brain resonances and the conscious experiences that they support. Neural Netw. 87, 38-95. doi: 10.1016/j.neunet.2016.11.003

Hameroff, S., and Penrose, R. (2014). Consciousness in the universe. A review of the "Orch OR" theory. Phys. Life Rev. 11, 39-78. doi: 10.1016/j.plrev.2013.08.002

Hu, H. (2016). Reward and aversion. Annu. Rev. Neurosci. 39, 297-324. doi: 10.1146/annurev-neuro-070815-014106

Jackson, F. (1986). What Mary didn't know. J. Philos. 83, 291-295. doi: $10.2307 / 2026143$ 
Jackson, R. R., and Cross, F. R. (2011). "Spider cognition" in Advances in insect physiology, Vol. 41 (London: Elsevier), 115-174.

Klein, C., and Barron, A. B. (2016). Insects have the capacity for subjective experience. Anim. Sent. 1, 1-19.

Koch, C., Massimini, M., Boly, M., and Tononi, G. (2016). Neural correlates of consciousness: progress and problems. Nat. Rev. Neurosci. 17, 307-321. doi: $10.1038 /$ nrn.2016.22

Lacalli, T. (2018). Amphioxus neurocircuits, enhanced arousal, and the origin of vertebrate consciousness. Conscious. Cogn. 62, 127-134. doi: 10.1016/j. concog.2018.03.006

Lamme, V. A. (2006). Towards a true neural stance on consciousness. Trends Cogn. Sci. 23, 571-579. doi: 10.1016/j.tics.2006.09.001

LeCun, Y., Bengio, Y., and Hinton, G. (2015). Deep learning. Nature 521:436. doi: $10.1038 /$ nature14539

LeDoux, J. E., and Brown, R. (2017). A higher-order theory of emotional consciousness. Proc. Natl. Acad. Sci. USA 114, E2016-E2025. doi: 10.1073/ pnas. 1619316114

Levine, J. (1983). Materialism and phenomenal properties: the explanatory gap. Pac. Philos. Q. 64, 354-361. doi: 10.1111/j.1468-0114.1983.tb00207.x

Ma, X., Hou, X., Edgecombe, G. D., and Strausfeld, N. J. (2012). Complex brain and optic lobes in an early Cambrian arthropod. Nature 490, 258-261. doi: 10.1038/nature11495

Mather, J. A., and Carere, C. (2016). Cephalopods are best candidates for invertebrate consciousness. Anim. Sent. 1, 1-3.

Mayr, E. (2004). What makes biology unique? Considerations on the autonomy of a scientific discipline. Cambridge: Cambridge University Press.

Merker, B. (2005). The liabilities of mobility: a selection pressure for the transition to consciousness in animal evolution. Conscious. Cogn. 14, 89-114. doi: 10.1016/S1053-8100(03)00002-3

Merker, B. H. (2016). Insects join the consciousness fray. Ani. Sent. 1, 1-3.

Mogensen, J., and Overgaard, M. (2017). Reorganization of the connectivity between elementary functions-A model relating conscious states to neural connections. Front. Psychol. 8:625. doi: 10.3389/fpsyg.2017.00625

Northcutt, R. G. (2012). Evolution of centralized nervous systems: two schools of evolutionary thought. Proc. Natl. Acad. Sci. USA 109(Suppl. 1), 10626-10633. doi: $10.1073 /$ pnas. 1201889109

Northoff, G. (2016). Slow cortical potentials and "inner time consciousness"-A neuro-phenomenal hypothesis about the "width of present". Int. J. Psychophysiol. 103, 174-184. doi: 10.1016/j.ijpsycho.2015.02.012

Nummenmaa, L., Hari, R., Hietanen, J. K., and Glerean, E. (2018). Maps of subjective feelings. Proc. Natl. Acad. Sci. USA 115, 9198-9203. doi: 10.1073/ pnas. 1807390115

Nunez, P. L. (2016). The new science of consciousness. Amherst, NY: Prometheus Books.

Panksepp, J. (2005). Affective consciousness: core emotional feelings in animals and humans. Conscious. Cogn. 14, 30-80. doi: 10.1016/j.concog.2004.10.004

Perry, C. J., Baciadonna, L., and Chittka, L. (2016). Unexpected rewards induce dopamine-dependent positive emotion-like state changes in bumblebees. Science 353, 1529-1531. doi: 10.1126/science.aaf4454

Perry, C. J., and Chittka, L. (2019). How foresight might support the behavioral flexibility of arthropods. Curr. Opin. Neurobiol. 54, 171-177. doi: 10.1016/j. conb.2018.10.014

Piccinini, G. (2015). Physical computation: A mechanistic account. Oxford: Oxford University Press.

Plotnick, R. E., Dornbos, S. Q., and Chen, J. (2010). Information landscapes and sensory ecology of the Cambrian radiation. Paleobiology 36, 303-317. doi: $10.1666 / 08062.1$
Primas, H. (2007). Non-Boolean descriptions for mind-matter problems. Mind Matter 5, 7-44.

Revonsuo, A. (2006). Inner presence: Consciousness as a biological phenomenon. Cambridge, MA: MIT Press.

Schiff, N. D. (2008). Central thalamic contributions to arousal regulation and neurological disorders of consciousness. Ann. N. Y. Acad. Sci. 1129, 105-118. doi: $10.1196 /$ annals.1417.029

Seth, A. (2009). "Functions of consciousness" in Elsevier encyclopedia of consciousness. ed. W. P. Banks (San Francisco: Elsevier), 279-293.

Seth, A. K., Baars, B. J., and Edelman, D. B. (2005). Criteria for consciousness in humans and other mammals. Conscious. Cogn. 14, 119-139. doi: 10.1016/j. concog.2004.08.006

Shao, L., Saver, M., Chung, P., Ren, Q., Lee, T., Kent, C. F., et al. (2017). Dissection of the Drosophila neuropeptide F circuit using a high-throughput two-choice assay. Proc. Natl. Acad. Sci. USA 114, E8091-E8099. doi: 10.1073/ pnas. 1710552114

Solms, M. (2019). The hard problem of consciousness and the free energy principle. Front. Psychol. 9:2714. doi: 10.3389/fpsyg.2018.02714

Stein, B. E., and Meredith, M. A. (1993). The merging of the senses. Cambridge, MA: MIT Press.

Strausfeld, N. J. (2012). Arthropod brains: evolution, functional elegance, and historical significance. Cambridge, MA: Belknap Press of Harvard University Press.

Thompson, E. (2007). Mind in life: Biology, phenomenology and the sciences of mind. Cambridge, MA: Harvard University Press.

Tononi, G., and Koch, C. (2015). Consciousness: here, there and everywhere? Phil. Trans. R. Soc. B 370:20140167. doi: 10.1098/rstb.2014.0167

Torday, J. S., and Miller, W. B. Jr. (2018). The cosmologic continuum from physics to consciousness. Prog. Biophys. Mol. Biol. 140, 41-48. doi: 10.1016/j. pbiomolbio.2018.04.005

Trestman, M. (2013). The Cambrian explosion and the origins of embodied cognition. Biol. Theory 8, 80-92. doi: 10.1007/s13752-013-0102-6

Tsuchiya, N., and van Boxtel, J. (2013). Introduction to research topic: attention and consciousness in different senses. Front. Psychol. 4:249. doi: 10.3389/ fpsyg.2013.00249

Tsuchiya, N., Wilke, M., Frässle, S., and Lamme, V. A. (2015). No-report paradigms: extracting the true neural correlates of consciousness. Trends Cogn. Sci. 19, 757-770. doi: 10.1016/j.tics.2015.10.002

Van Swinderen, B., and Andretic, R. (2011). Dopamine in Drosophila: setting arousal thresholds in a miniature brain. Proc. R. Soc. Lond. B Biol. Sci. doi: $10.1098 /$ rspb.2010.2564

Vierck, C. J., Whitsel, B. L., Favorov, O. V., Brown, A. W., and Tommerdahl, M. (2013). Role of primary somatosensory cortex in the coding of pain. Pain 154, 334-344. doi: 10.1016/j.pain.2012.10.021

Von Bertalanffy, L. (1952). Problems of life; an evaluation of modern biological thought. Oxford, England: Wiley.

Conflict of Interest Statement: The authors declare that the research was conducted in the absence of any commercial or financial relationships that could be construed as a potential conflict of interest.

Copyright $\odot 2019$ Feinberg and Mallatt. This is an open-access article distributed under the terms of the Creative Commons Attribution License (CC BY). The use, distribution or reproduction in other forums is permitted, provided the original author(s) and the copyright owner(s) are credited and that the original publication in this journal is cited, in accordance with accepted academic practice. No use, distribution or reproduction is permitted which does not comply with these terms. 